\title{
Understanding demand for COVID-19 antibody testing
}

by Marta Serra Garcia and Nora Szech

No. 140 | MAY 2020

\section{WORKING PAPER SERIES IN ECONOMICS}

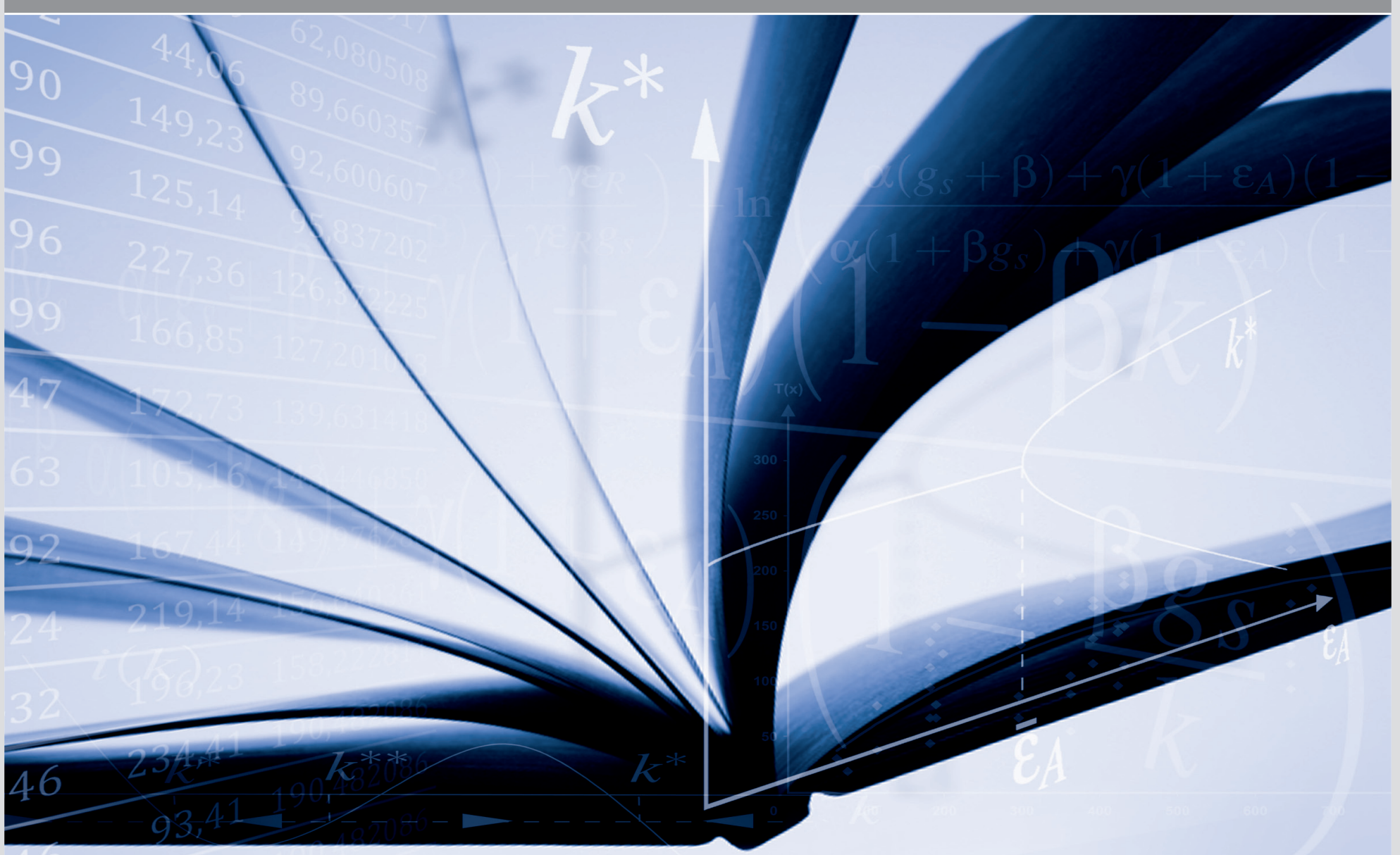




\section{Impressum}

Karlsruher Institut für Technologie (KIT)

Fakultät für Wirtschaftswissenschaften

Institut für Volkswirtschaftslehre (ECON)

Kaiserstraße 12

76131 Karlsruhe

KIT - Die Forschungsuniversität in der Helmholtz-Gemeinschaft

Working Paper Series in Economics

No. 140, May 2020

ISSN 2190-9806

econpapers.wiwi.kit.edu 


\title{
Understanding Demand for COVID-19 Antibody Testing
}

\section{Authors:}

Marta Serra Garcia, UCSD, CESifo, mserragarcia@ucsd.edu

Nora Szech, KIT, WZB, CESifo, nora.szech@kit.edu

22 May 2020

Preliminary and Incomplete

\begin{abstract}
We study individual demand for COVID-19 antibody tests in an incentivized study on a representative sample of the US population. Almost 2,000 participants trade off obtaining an athome test kit against money. At prices close to zero, 80 percent of individuals want the test. However, this broad support of testing falls sharply with price. Demand decreases by 19 percentage points per $\$ 10$ price increase. Demand for testing increases with factors related to its potential value, such as age, increased length and strength of protective immunity from antibodies, and greater uncertainty about having had the virus. Willingness to pay for antibody tests also depends on income, ethnicity and political views. Black respondents show significantly lower demand than white and Hispanic respondents, and Trump-supporters demonstrate significantly lower demand for testing. The results suggest that charging even moderate prices for antibody tests could widen health inequalities.
\end{abstract}

JEL: D81, D91, I12, I18

Keywords: Coronavirus, COVID-19, Antibody Tests, Information Preferences, Beliefs, Uncertainty 
The COVID-19 pandemic has led to one of the largest death tolls in history and an unprecedented shutdown of economic activity worldwide. Having reduced the spread of the virus, some governments are starting to carefully open up again. As a major part of the return to "new normal", testing is discussed in many countries, e.g., Germany (Dorn et al., 2020) or the US (Altmann et al., 2020). However, forcing such tests or requiring "immunity passports" seem highly controversial and problematic (Miller, 2020; Studdert and Hall, 2020). In a country of over 300 million inhabitants such as the US, knowledge about antibody status may ultimately depend on individuals' willingness to test themselves privately.

This paper measures individual willingness to pay for private COVID-19 antibody tests. We conducted an incentivized study on a representative sample of almost 2,000 U.S. participants. When the study was launched, no at-home testing kit had been approved by the U.S. Food and Drug Administration (FDA) yet (U.S. FDA, 2020). We confronted participants with different scenarios. In each of them, we elicited willingness to pay for antibody testing. Four in five individuals would like to get tested, if it was basically for free. Yet, this changes drastically with price. For example, demand drops by half when the price of the test is $\$ 20$ or more. Thus, the data demonstrate that price plays an important role.

Demand for the test is influenced by test value. For example, older people and those who have experienced more deaths due to COVID-19 demand the test more frequently. Beliefs about antibody status also matter for demand. It has been argued that people may overestimate chances of having had Covid-19 (Mandavilli, 2020). Our data reveals that indeed, compared to CDC estimates, most people tend to overestimate chances of having been infected. Yet most people feel uncertain. Test demand increases with this uncertainty.

Several personal factors affect the demand for testing as well, such as income, age, ethnicity, and political views. We document that people of black ethnicity demand the test significantly less often. They are willing to pay approximately $\$ 5$ less than whites for testing, even though they may be at higher risk of infection (Hlavinka, 2020). The data also show that Trumpsupporters demonstrate lower test demand, while those who approve of Dr. Fauci's performance display significantly higher test demand.

Many studies on the prevalence of COVID-19 antibodies in populations so far rely on volunteers. Participation may often come with an extra effort for participants. Our data indicate that such an approach unlikely leads to a representative sample of the population as preferences 
for testing vary with many socio-economic characteristics. Even when controlling for some characteristics, such as age, gender and ethnicity, other factors such as political orientation will unlikely be controlled for. For example, Trump supporters may not only display a lower interest in testing, but also protect themselves less from Covid-19. If they take the disease less seriously but also test less, voluntary testing will systematically underestimate the prevalence of infection rates in the US population.

Existing research has demonstrated that in some cases people avoid medical testing. For example, people at risk of the severe genetic Huntington's Disease often opt against testing (see Caplin and Leahy 2001, Oster et al. 2013, Schweizer and Szech 2018). The same is true for

people at risk of HIV, or Alzheimer's (see Hertwig and Engel 2016 and Golman et al., 2017, for overviews on such deliberate ignorance). In this light, it may be good news that four out of five US citizens want an antibody test for COVID-19 when it comes for free. Thunström et al. (2020a, b) find similar willingness to get tested for the disease or vaccine take-up in hypothetical (and costless) decisions. Yet, our results demonstrate that this demand falls sharply with price. This result is important for policymakers that are "opening up" their economies and societies. Furthermore, demand for the test is not only driven by its value, but also by other factors such as income, race and political orientation. Pricing decisions could therefore have large impacts on health inequality.

\section{Experimental Design}

Our study is based on 1,984 participants, selected to represent the US population, who took part in our anonymous study. Each individual decided, in eight different testing scenarios, whether they preferred an antibody at-home testing kit or a voucher. The value of the voucher varied from $\$ 0.50$ to $\$ 30$ in each scenario, and came in the form of an Amazon gift card. Across scenarios, the protective immunity of antibodies varied. A positive test result could lead to a likelihood of protection from COVID-19 with $50 \%, 70 \%, 90 \%$, or $99 \%$ chance. The expected length of protection also varied. It was either 3, 6, or 12 months. Eight out of the 12 possible testing scenarios were randomly chosen and presented to the individual in random order. Individuals knew that about 1 in 25 of them would be chosen randomly and one of their decisions would be implemented. We explained that their decisions would be implemented using the scenario that most closely fits the tests that become available in upcoming weeks. At the time 
of the study, it was uncertain which scenario would fit best to the test that would eventually become available on the market, and the protective immunity a positive test result may provide. Therefore, all scenarios were potentially relevant based on existing research (Altmann et al., 2020; Sheridan, 2020). We calculate each individual's willingness to pay for the test in each scenario based on the first voucher value for which the individual chooses the voucher over the test. This provides a maximum willingness to pay. More than $94 \%$ of individuals make consistent decisions and the analyses focus on them. After making their testing decisions, individuals responded to several questions about their beliefs and experiences with COVID-19, and individual characteristics. They were also presented with the choice between 2 antibody tests, instead of 1 , and vouchers ranging between $\$ 0.50$ and $\$ 75$. It took about 12 minutes to participate in our study. Data elicitation took place from May 6 to May, 182020.

\section{Results}

Most people express an interest in testing for antibodies. About 80 percent of individuals demand a test when it costs less than $\$ 2$. This result is robust to the different strength and length of protective immunity a positive test result may provide. As price increases demand drops, down to less than $20 \%$ when the price is $\$ 30$ and the chance of protective immunity is rather low, 50\% (see Figure 1). On average, a \$10-dollar increase in the cost of the antibody test reduces demand by 19 percentage points (see Table $1, \mathrm{p}<0.001$ ).

Increases in the length of the protective immunity offered by the test increase demand. As shown in Table 1, an increase in the length of immunity of 1 month, increases test demand by 0.8 percentage points. In other words, people pay $\$ 0.95$ more for a test, if a positive results result indicates protection from COVID-19 for 12 months than for 6 months. The increase in willingness to pay is not linear: it is stronger when immunity increases from 6 to 3 months (\$1.45), than when immunity increases from 6 to 12 months. This suggests that, given the current ambiguity on what the next months may bring, individuals mostly focus on the near future.

Protection levels affect demand. An increase of 1 percentage point in the chance of protection increases demand by 0.3 percentage points. For example, people pay $\$ 0.90$ more for a test, if a positive test result leads to a protection level of 99 percent than of 90 percent. For comparison, according to the $\mathrm{CDC}$, the vaccine against measles has led to more than a 99 percent reduction of cases (Center for Disease Control and Prevention, 2019). In contrast, the flu vaccine 
needs to be adapted to each new flu season and often displays an effectiveness of about 50 percent (Center for Disease Control and Prevention, 2020). Our results demonstrate that for COVID-19, people care a lot about protection levels.

Using our elicitation method, we can further compare how individuals trade off increases in length and strength of protection. An increase in the chance of protection of 27 percentage points is equivalent to an increase in the length of protection of 10 months. Increases in strength and length of protective immunity also decrease the effect of price on demand (see columns (2)-(4) of Table 1). For example, even at a price of $\$ 30,50 \%$ of individuals demand the test when the length of immunity is 12 months and the chance of protection is very high, i.e., $99 \%$.

\section{[INSERT FIGURE 1 and TABLE 1 HERE]}

We also evaluate demand when individuals are offered two tests, instead of one. If the price of two tests is low, as with one test, most individuals choose the tests. As the price increases to $\$ 50$ or $\$ 75$, demand drops to $44 \%$ and $36 \%$, respectively. This reveals that a minority of people would be willing to pay prices above $\$ 75$ for testing (see detailed results in the SOM). About 33 percent of individuals say they would use both tests on themselves, while 63 percent say they would pass one on to another person.

Demand for the tests varies strongly by demographic. Figure 2 shows the maximum willingness to pay for an antibody test, averaged across scenarios. As shown in Figure 2 and columns (3)-(4) of Table 1, there is a significant increase in demand in older individuals, consistent with older individuals being at higher risk from death and other complications from COVID-19. Across ethnicities, demand is significantly lower for non-Hispanic blacks, compared to whites, and also to Hispanic individuals. On average, non-Hispanic blacks demand the test 11 to 13 percentage points less than whites and are willing to pay $\$ 4.10$ less than whites $(\$ 15.28$ compared to $\$ 19.38$ ). As income increases, individuals are willing to pay more for the test, as one would expect as the price becomes a less important part of the household's budget. Individuals' work situation does not significantly affect demand. Relative to those who work from home (33\% of the sample), those who are essential workers or lost their job due to COVID19 do not exhibit significantly different demand. Only those who are not employed, such as students or retired individuals, exhibit a weakly lower demand. 
[INSERT FIGURE 2 HERE]

A central concern is that individuals overestimate their infection status, misattributing colds, allergies or regular flu to COVID-19. The New York Times stated in May that almost everybody in New York believed they had COVID-19 already (Mandavilli, 2020). In our representative sample of the US, we find that on average, people believe they had been infected already with a likelihood of 25 percent. This is very likely an over-estimate (see SOM for a US-state specific comparison to CDC estimates). Yet few people are certain or almost certain they have had COVID-19. Much more common are beliefs of 0 (19\% of the sample), 20 (the median is 18), or 50 percent (see Figure 3).

Beliefs about infection of individuals can be compared with prevalence rates estimated by the Center for Disease Control and Prevention (CDC). We use the data as of May 10, 2020, published by the CDC for each state (see SOM for detailed results by state). The CDC provides an estimated range of percentage of positive cases. This range can be $0-5 \%, 6-10 \%, 11-20 \%, 21$ 30\%, 31-40\%. Comparing individual responses across states, we find that in most states (86\%), the average believed status of infection is above the CDC estimated range. For example, while the estimated range of positive cases is 6-10\% in California, the average belief of participants in California regarding the likelihood that they have had COVID-19 is 25\%. In $10 \%$ of the states, beliefs coincide with the CDC range, while in $4 \%$ of the states, individuals report a belief below that of the CDC estimated range. These results suggest that, while a majority of individuals believe that the chance they have had the virus is low, it may still be above official estimates.

\section{[INSERT FIGURE 3 HERE]}

Consistent with standard information economics, we find that willingness to pay for testing is significantly related to individuals' self-reported beliefs about their infection status. Those who are certain to have had or not have had the virus, report the lowest willingness to take the test. The more uncertain individuals are about their infection status, the more they are willing to pay for testing as shown in Figure 3. Thus, patterns are consistent with individuals perceiving the test as providing instrumental information about infection status. We also elicited individuals' beliefs 
that others in close proximity had been infected. This belief is highly correlated with own belief (Spearman correlation coefficient $=0.72, \mathrm{p}$-value $<0.001)$ and does not have an independent effect on demand for the test.

Individuals' willingness to pay for the test is also related to their personal knowledge of people infected with the virus. The number of deaths in the individuals' social circle is related to their demand for the test (column (4) of Table 1). While a relationship can also be found when considering COVID-19 cases instead of deaths, the relationship is generally weaker, suggesting that the largest driver of willingness to get tested is deaths, the worst outcome, rather than infections. Not surprisingly, those who have already been tested for COVID-19, approximately $4 \%$ of the sample, display a lower demand for the test. At the same time, those individuals who report being worried or very worried about COVID-19 report a higher demand.

Decisions about taking an antibody test may also depend on the understanding of probability values and updating information in a statistically correct way. A concern has been that antibody tests that exhibit low sensitivity, i.e., often showing a positive result for antibodies while the individual does not have any, can mislead people if they cannot account for the error rate of tests (Mandavilli, 2020; Hagmann et al., 2020). We therefore included four questions on statistical knowledge. Two questions were on probability estimates (regarding the chances of particular outcomes of a die roll). Overall, $42 \%$ of participants provided a correct answer to both questions, $40 \%$ provided a correct answer to 1 question, and 18\% did not answer either question correctly. We also added two incentivized questions to measure failures in Bayesian updating (Tversky and Kahnemann, 1974). These questions presented individuals with antibody tests that had an accuracy of either $90 \%$ or $95 \%$ (i.e., correctly detected antibodies with 90 or 95 chance), and a prevalence of COVID-19 infections of $5 \%$ or $20 \%$. Each person saw two randomly drawn scenarios and was incentivized to correctly guess how likely a positive test result indicated the presence of antibodies. A common mistake in such questions is to ignore the "base rate" and report an accuracy equivalent to 90 or $95 \%$. In the sample, $35 \%$ of participants exhibit Bayes rate neglect (Tversky and Kahnemann, 1974), while 42\% of participants provide an answer that is within 10 percentage points of the correct answer. We aggregate answers to the four questions on statistical knowledge into an index, adding all correct responses and standardizing it. Statistics knowledge is related to a stronger demand of the test. A one standard deviation increase in statistics knowledge is related to an increase in demand of 1.5 percentage points. This 
indicates that, despite the fact that some individuals understand the potential limitations of antibody tests very well, they value them (see column (4) of Table 1).

In addition to personal characteristics and beliefs, an individual's perception of how public authorities deal with the pandemic may affect test demand (Briscese et al., 2020; Fetzer et al., 2020). Role models may have significant influence. Therefore, individuals rate the performance of Dr. Fauci and of President Trump during the Coronavirus crisis, from 0 (extremely bad) to 10 (extremely good). Individuals who report a high degree of approval of Dr. Fauci exhibit a much higher willingness to pay for antibody tests. By contrast, those who rate the performance of President Trump as high exhibit a significantly lower willingness to pay for testing (see Figure 4). This is consistent with ongoing research comparing individual perceptions over time (Fetzer et al., 2020), and also shows that within the US, perceptions of competence among public authorities could significantly influence individual behaviors during the pandemic. Of course, here, we cannot exclude reverse causality in the sense that people who do not like testing approve more of President Trump.

\section{[INSERT FIGURE 4 HERE]}

The value of the test also ultimately relies on individuals' planned use of the information that they have (or do not have) antibodies. If individuals took the test and it detected antibodies, they indicated that they would engage in indoors and outdoors social activities, visit restaurants and malls, and return to work over $20 \%$ of the time. The largest fraction (over $40 \%$ ) however indicated that they would not engage in any of these "risky" behaviors. This reveals that, for a substantial fraction of people, knowledge that they had antibodies would not be sufficient to lead to riskier, social behaviors. This suggests significant caution among individuals and perhaps assuages the concern that positive antibody test results could be interpreted as "freedom" from social distancing measures by most people.

\section{Conclusion}

Our results demonstrate that most people want an antibody test. Four in five US citizens demand a test if prices are close to zero. Yet this demand drops sharply as prices increase. At a cost of $\$ 20$, demand roughly drops by half. People of black ethnicity are significantly less willing to pay 
for testing than other ethnicities. Yet research suggests that they may be at higher risk from Covid-19, not only for socio-economic, but also for genetic reasons (Cao et al., 2020). An analysis of past pandemics going back almost 1,000 years demonstrates that pandemics typically increase inequality (Wade, 2020). Policy makers should be aware that also in this pandemic inequality may rise. If testing comes at a private cost, this could happen even more so, damaging groups of society that were already vulnerable before. Other hard-hit countries are currently aiming to provide free antibody testing (Nikolskaya and Voronova, 2020). From our data, this policy may be a wise choice. 


\section{References}

Dorn, F., Khailaie, S., Stockli, M., Binder, S., Lange, B., Peichl, A., Vanella, P., Wollmerhauser, T., Fuest, C., Meyer-Hermann, M. (2020). Das gemeinsame Interesse von Gesundheit und Wirtschaft: Eine Szenarienrechnung zur Eindämmung der Corona-Pandemie. Ifo Schnelldienst digital 6/2020.

Altmann DM, Boyton RJ, Douek DC (2020) What policy makers need to know about COVID19 protective immunity. The Lancet. 395(10236):1527-1529.

Miller J (2020, May 14) Europe pins hopes on antibody tests to avoid second virus wave. Reuters. https://www.reuters.com/article/us-health-coronavirus-antibody-testing/europe-pinshopes-on-antibody-tests-to-avoid-second-virus-wave-idUSKBN22Q2VY

Studdert D., and Hall M. (2020) Law issues - Disease Control, Civil Liberties, and Mass Testing - Calibrating Restrictions during the Covid-19 Pandemic. The New England Journal of Medicine. https://www.nejm.org/doi/10.1056/NEJMp2007637

U.S. Food and Drug Administration (2020, May). Emergency Use Authorizations. U.S. Government, U.S. Food and Drug Administration. https://www.fda.gov/medicaldevices/emergency-situations-medical-devices/emergency-use-authorizations\#covid19ivd

Mandavilli, A., (2020, May 7). After Recovery From the Coronavirus, Most People Carry Antibodies. New York Times, https://www.nytimes.com/2020/05/07/health/coronavirusantibody-prevalence.html.

Hlavinka, E. (2020, May). COVID-19 Killing African Americans at Shocking Rates. MedPage Today https://www.medpagetoday.com/infectiousdisease/covid19/86266

Caplin, A., Leahy J. (2001). Psychological Expected Utility Theory and Anticipatory Feelings. Quarterly Journal of Economics, 116, 55-79.

Oster E., Dorsey R., Shoulson, I. (2013). Optimal Expectations and Limited Medical Testing: Evidence from Huntington Disease. American Economic Review, 103, 804-830.

Schweizer N., Szech N. (2018) Optimal Revelation of Life-Changing Information. Management Science 64 (11) 4967-5460.

Hertwig, R., Engel, C. (2016) Homo Ignorans: Deliberately Choosing Not to Know. Perspectives on Psychological Science 11(3), 359-372.

Golman, R., Hagmann, D., Loewenstein, G. (2017) Information Avoidance. Journal of Economic Literature 55 (1), 96-135.

Thunström L., Ashworth, M., Shogren, J., Newbold, S., Finnoff, D. (2020a) Testing for COVID-19: Willful ignorance or selfless behavior? Behavioural Public Policy, forthcoming. 
Thunström, L., Ashworth, M., Finnoff, D., Newbold, S. (2020b). Hesitancy Towards a COVID19 Vaccine and Prospects of Herd Immunity (May 6, 2020). Available at SSRN: https://ssrn.com/abstract $=3593098$

Sheridan, C. (2020, April 17) Fast, portable tests come online to curb coronavirus pandemic. Nature Biotechnology 38, 515-518. https://www.nature.com/articles/d41587-020-00010-2

Center for Disease Control and Prevention (2019, June). Vaccine for Measles. U.S. Department of Health and Human Services, Center for Disease Control and Prevention, https://www.cdc.gov/measles/vaccination.html.

Center for Disease Control and Prevention (2020, February). CDC Seasonal Flu Vaccine Effectiveness Studies. U.S. Department of Health and Human Services, Center for Disease Control and Prevention, https://www.cdc.gov/flu/vaccines-work/effectiveness-studies.htm.

Vogel G (2020, April 21) Antibody surveys suggesting vast undercount of coronavirus infections may be unreliable. Science. https://www.sciencemag.org/news/2020/04/antibodysurveys-suggesting-vast-undercount-coronavirus-infections-may-be-unreliable\#

Mandavilli, A. (2020, April 28) Coronavirus Antibody Tests: Can you trust the results? The New York Times, https://www.nytimes.com/2020/04/24/health/coronavirus-antibodytests.html

Hagmann, D., Loewenstein, G., Ubel, P. (2020, April 30). Antibody tests might be deceptively dangerous blame the math. The Washington Post, https://www.washingtonpost.com/outlook/2020/04/30/antibody-tests-might-be-deceptivelydangerous-blame-math/

Tversky A, Kahneman D (1974) Judgment under Uncertainty: Heuristics and Biases. Science 185 (4157), 1124-1131.

Briscese G., Lacetera, N., Macis, M., Tonin, M. (2020) Compliance with COVID-19 SocialDistancing Measures in Italy: The Role of Expectations and Duration. NBER Working Paper No. 26916.

Fetzer, T., Witte, M., Hensel, L., Jachimowicz, J., Haushofer, J., Ivchenko, A., Caria, S., Reutskaja, E., Roth, C.P., Fiorin, S., Gomez, M., Kraft-Todd, G., Gotz, F., Yoeli, E. (2020). Global Behaviors and Perceptions in the COVID-19 Pandemic. NBER Working Paper No. 27082.

Cao, Y., Li, L., Feng, Z., Wan, S., Huang, P., Sun, X., Wen, F., Huang, X., Ning, G., Wang, W. (2020). Comparative genetic analysis of the novel coronavirus (2019-nCoV/SARS-CoV-2) receptor ACE2 in different populations. Nature Cell Discovery 6, 11.

Wade, L. (2020). An unequal blow. Science 368, 6492, 700-703. 
Nikolskaya, P., Voronova, T., (2020, May 15). Russian coronavirus cases above 260,000 as Moscow launches antibody tests. Reuters, https://www.reuters.com/article/us-healthcoronavirus-russia-cases/russian-coronavirus-cases-above-260000-as-moscow-launchesantibody-tests-idUSKBN22R0ZD 


\title{
Understanding Demand for COVID-19 Antibody Testing
}

\author{
by Marta Serra-Garcia and Nora Szech
}

Figures and Tables

May 21, 2020

COVID-19 Antibody Test Demand,

by Strength and Length of Protective Immunity
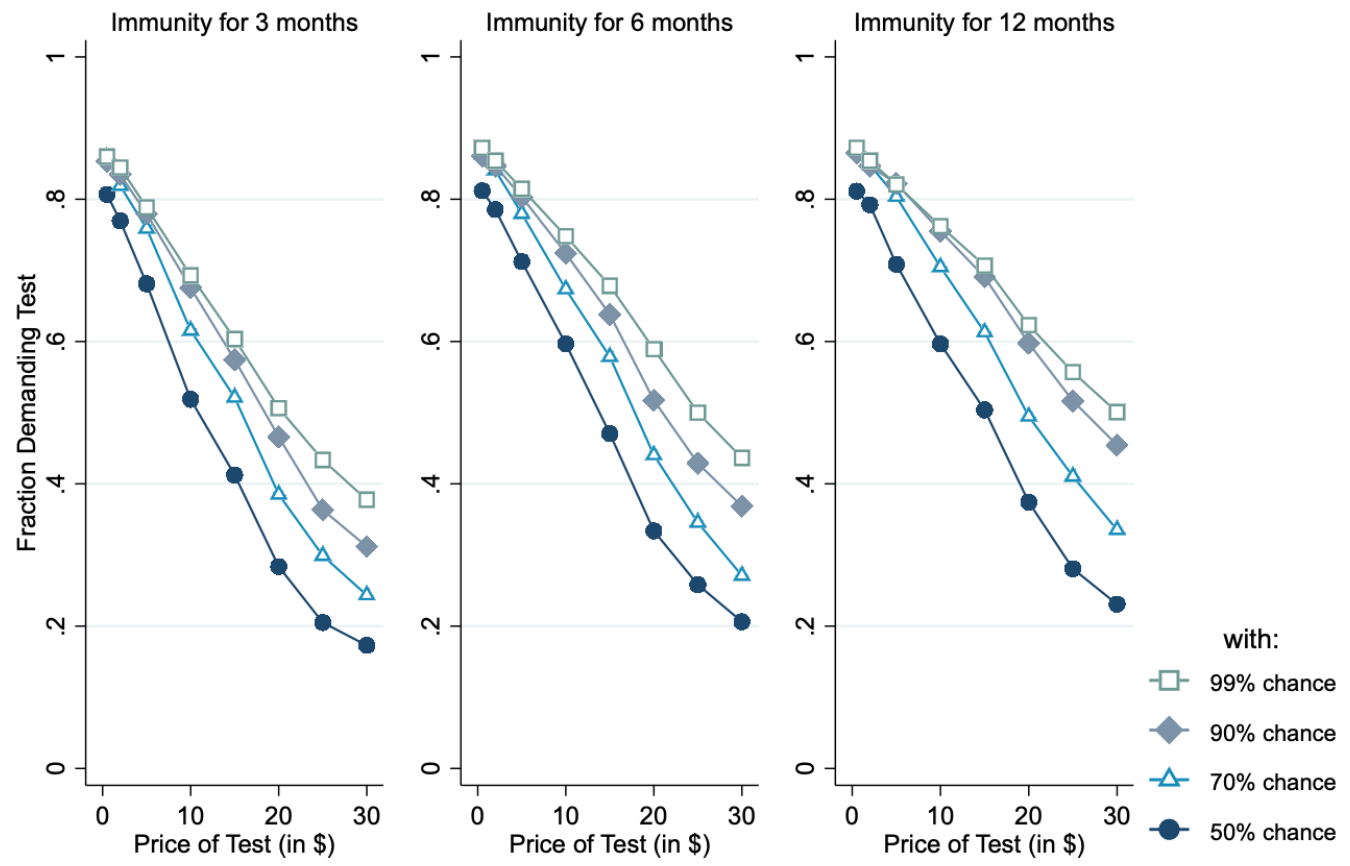

Figure 1. This figure displays the fraction of respondents choosing the COVID-19 antibody tests, for each price. Demand is shown for the cases in which protective immunity lasts 3 months (left), 6 months (center), and 12 months (right). In each case, the strength of protective immunity varies between a $99 \%, 90 \%, 70 \%$ or $50 \%$ chance that antibodies offer protection against COVID-19. 


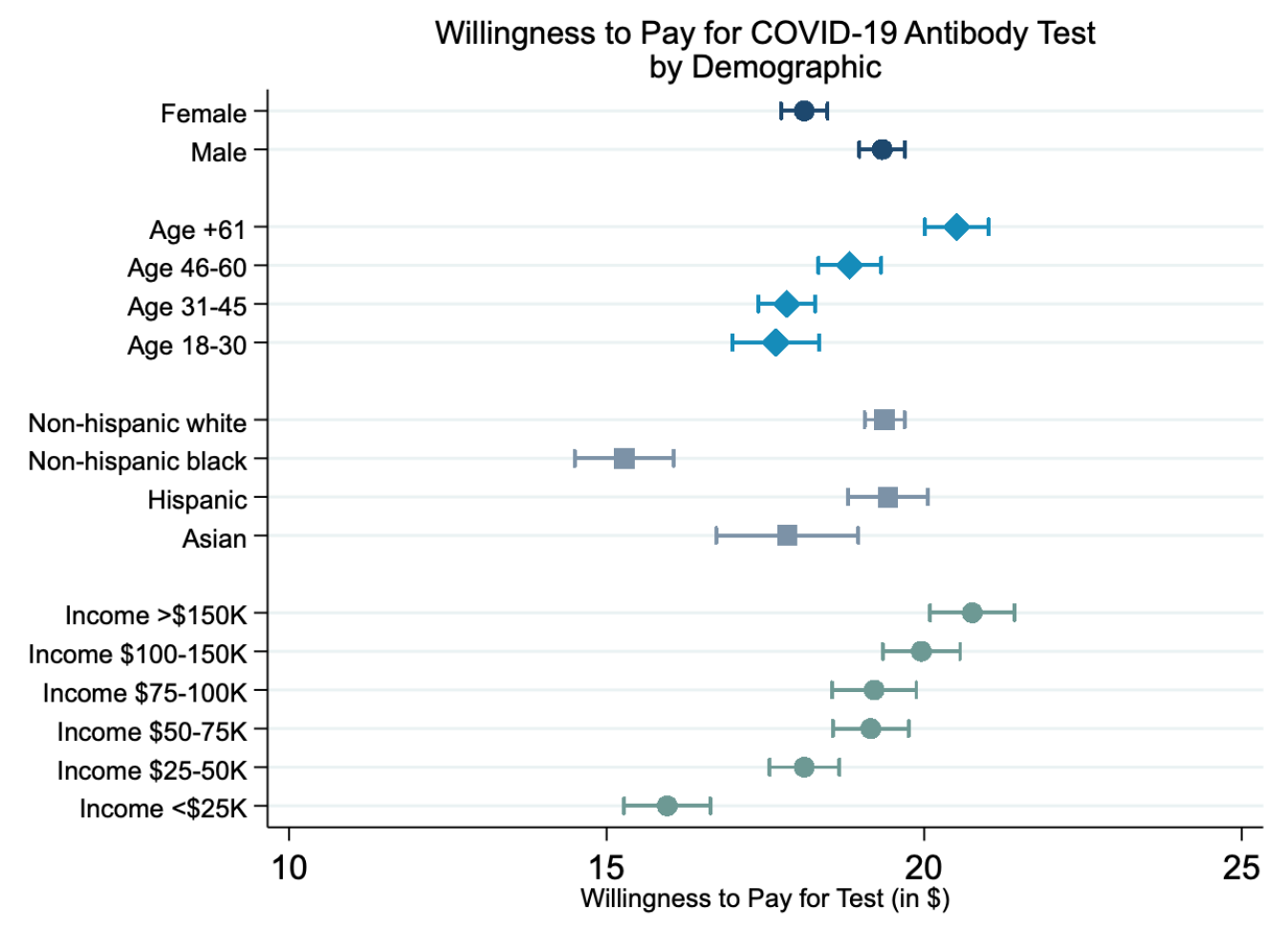

Figure 2. This figure displays the average willingness to pay for COVID-19 antibody tests, by gender, age, ethnicity and household income. The shares of each demographic characteristic are representative of the US population. The horizontal bars around each average represent $\pm 1 \mathrm{SE}$. 
Belief About COVID-19 Infection and

Willingness To Pay for Antibody Test

(a) Belief Distribution

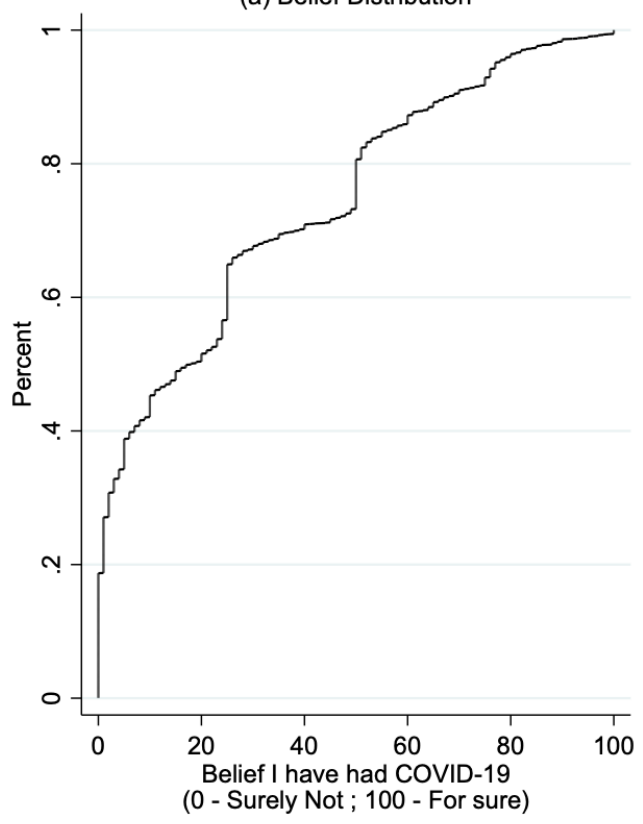

(b) Belief and Willingness to Pay

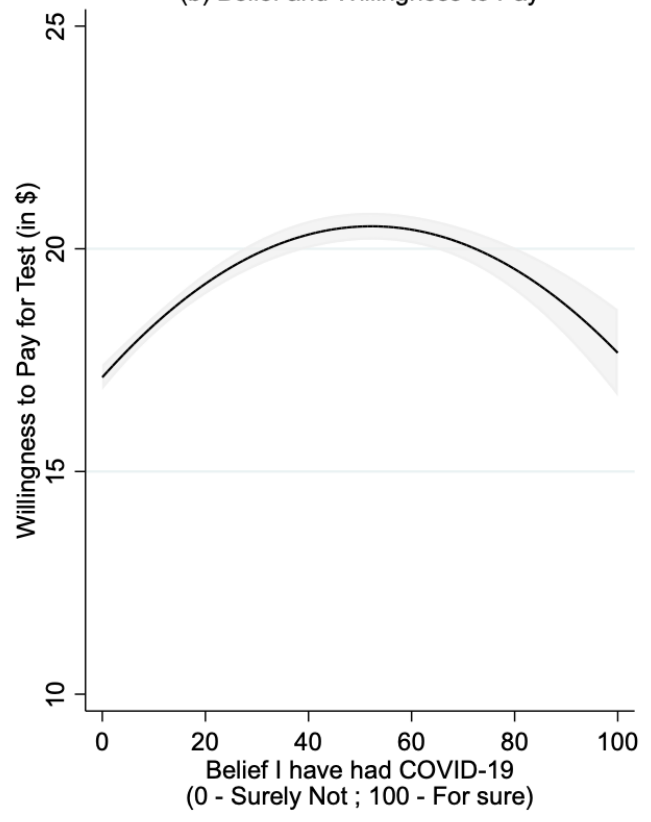

Figure 3. This figure displays the distribution of beliefs about COVID-19 Infection status, as of May 6-18 of 2020 (left panel), and the relationship between this belief and individuals' willingness to pay for COVID-19 antibody tests (right panel). The black line is a polynomial fitted regression for the individual's average willingness to pay, across all scenarios, as a function of the individual's belief about COVID-19 status with 95\% confidence interval (shaded grey area). 


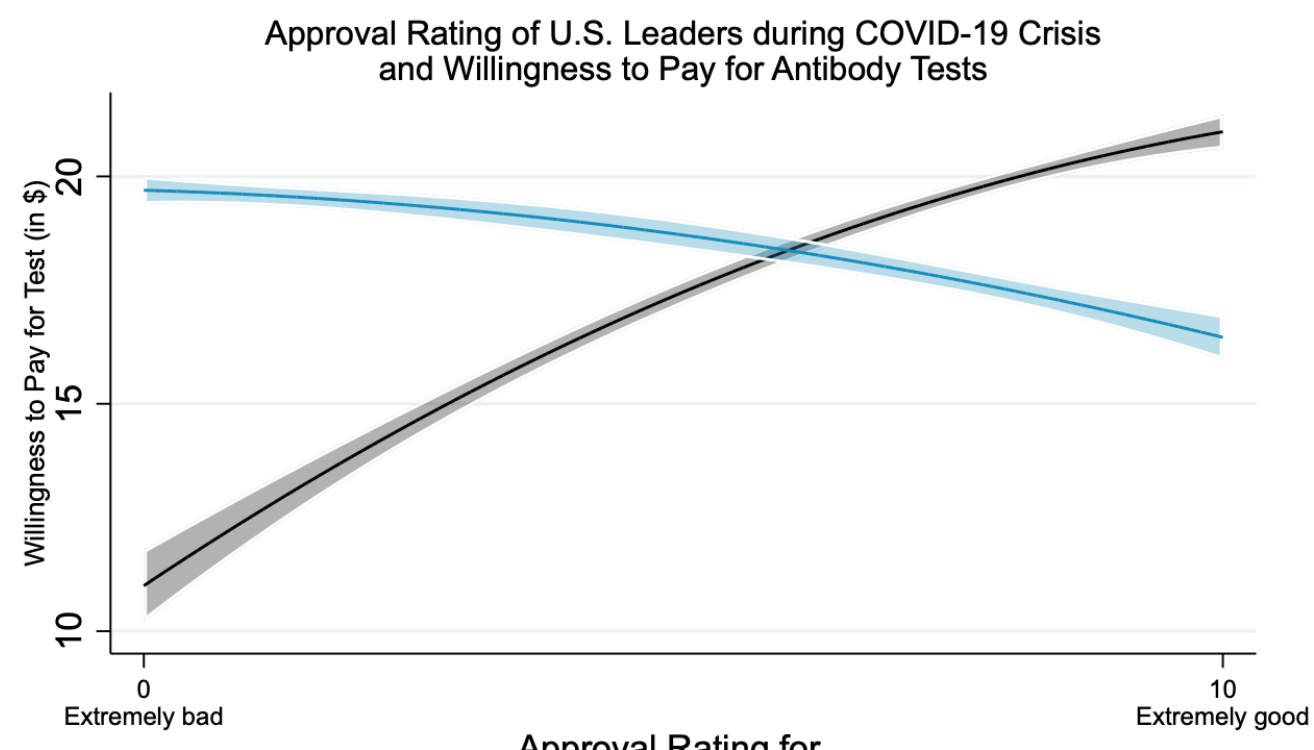

Approval Rating for...

Figure 4. This figure displays the results of polynomial fitted regressions for the individual's average willingness to pay for antibody tests, across all scenarios, as a function of the individual's approval of President Trump's (in blue) and Dr. Fauci's (in black) performance during the COVID-19 crisis. The shaded areas in each case indicate $95 \%$ confidence intervals. 


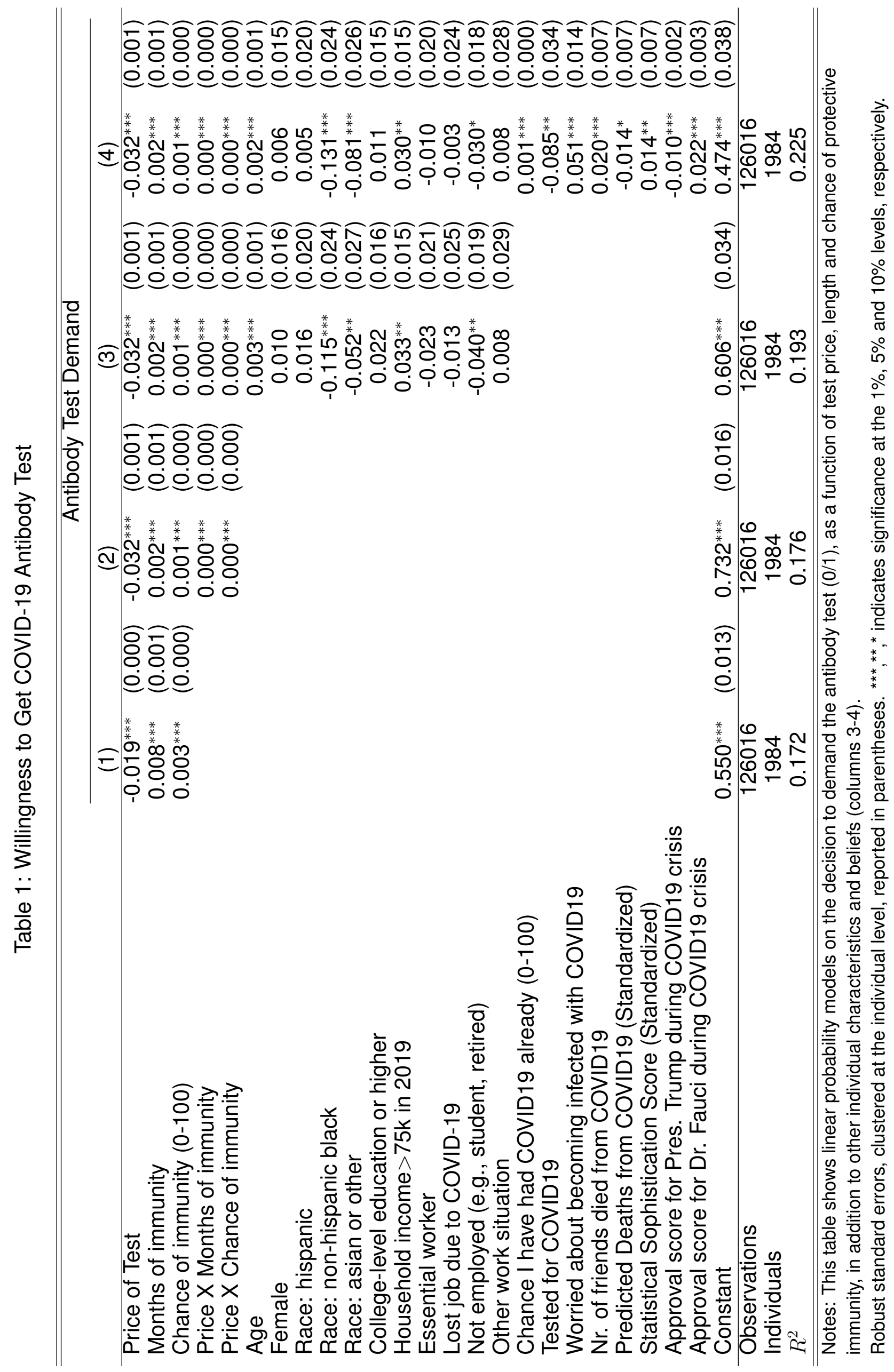




\section{Supplementary Online Materials}

\section{A Additional Results}

\section{A.1 Descriptive Statistics of the Sample}

Table A.1: Sociodemographic Characteristics of the Sample

\begin{tabular}{lc}
\hline \hline & $(1)$ \\
& mean \\
\hline Female & 0.51 \\
Age & 47.33 \\
Race: non-hispanic white & 0.61 \\
Race: non-hispanic black & 0.13 \\
Race: hispanic & 0.18 \\
Race: asian or other & 0.08 \\
Household income $>$ 75k in 2019 & 0.42 \\
High school or less & 0.28 \\
College-level education or higher & 0.67 \\
Lives in city & 0.31 \\
Lives in suburban area & 0.51 \\
Lives in rural area & 0.18 \\
Democrat & 0.39 \\
Republican & 0.27 \\
Independent & 0.34 \\
Essential worker & 0.18 \\
Working from home & 0.29 \\
Lost job due to COVID-19 & 0.12 \\
Not employed (e.g., student, retired) & 0.33 \\
Other work situation & 0.08 \\
\hline Observations & 1984 \\
\hline \hline
\end{tabular}


Table A.2: Beliefs and Experiences during COVID-19 Crisis

\begin{tabular}{lc}
\hline \hline & $(1)$ \\
& All \\
mean \\
\hline Tested for COVID19 & 0.04 \\
Chance I have had COVID19 already (0-100) & 25.44 \\
Chance close others have had COVID19 already (0-100) & 25.55 \\
COVID19 Dangerous due to underlying conditions & 0.24 \\
Worried about becoming infected with COVID19 & 0.36 \\
Nr. of friends infected with COVID19 & 0.79 \\
Nr. of friends died from COVID19 & 0.18 \\
Predicted Deaths from COVID19 within 1 month & 118802.73 \\
Approval score for President Trump during COVID19 crisis & 3.96 \\
Approval score for Dr. Fauci during COVID19 crisis & 6.80 \\
\hline Observations & 1984 \\
\hline \hline
\end{tabular}




\section{A.2 Demand and Willingness to Pay}

Table A.3: Antibody Test Demand, by Price, Length and Strength of Immunity

\begin{tabular}{|c|c|c|c|c|c|c|c|c|c|}
\hline & $\begin{array}{c}(1) \\
\text { All } \\
\text { mean }\end{array}$ & $\begin{array}{c}(2) \\
P=0.50 \\
\text { mean }\end{array}$ & $\begin{array}{c}(3) \\
P=2 \\
\text { mean }\end{array}$ & $\begin{array}{c}(4) \\
P=5 \\
\text { mean }\end{array}$ & $\begin{array}{c}(5) \\
P=10 \\
\text { mean }\end{array}$ & $\begin{array}{c}(6) \\
P=15 \\
\text { mean }\end{array}$ & $\begin{array}{c}(7) \\
P=20 \\
\text { mean }\end{array}$ & $\begin{array}{c}(8) \\
P=25 \\
\text { mean }\end{array}$ & $\begin{array}{c}(9) \\
P=30 \\
\text { mean }\end{array}$ \\
\hline 3 month - $50 \%$ & 0.48 & 0.81 & 0.77 & 0.68 & 0.52 & 0.41 & 0.28 & 0.21 & 0.17 \\
\hline 6 month - $50 \%$ & 0.52 & 0.81 & 0.79 & 0.71 & 0.60 & 0.47 & 0.33 & 0.26 & 0.21 \\
\hline 12 month - $50 \%$ & 0.54 & 0.81 & 0.79 & 0.71 & 0.60 & 0.50 & 0.37 & 0.28 & 0.23 \\
\hline 3 month - $70 \%$ & 0.56 & 0.86 & 0.82 & 0.76 & 0.62 & 0.52 & 0.39 & 0.30 & 0.24 \\
\hline 6 month - $70 \%$ & 0.60 & 0.86 & 0.84 & 0.78 & 0.67 & 0.58 & 0.44 & 0.35 & 0.27 \\
\hline h - $70 \%$ & 0.63 & 0.87 & 0.85 & 0.80 & 0.70 & 0.61 & 0.49 & 0.41 & 0.34 \\
\hline 3 month - $90 \%$ & 0.61 & 0.85 & 0.83 & 0.78 & 0.68 & 0.57 & 0.47 & 0.36 & 0.31 \\
\hline 6 month - $90 \%$ & 0.65 & 0.86 & 0.85 & 0.80 & 0.72 & 0.64 & 0.52 & 0.43 & 0.37 \\
\hline 12 month - $90 \%$ & 0.69 & 0.86 & 0.85 & 0.82 & 0.75 & 0.69 & 0.60 & 0.52 & 0.45 \\
\hline $3 \mathrm{mo}$ & 0.64 & 0.86 & 0.84 & 0.79 & 0.69 & 0.60 & 0.51 & 0.43 & 0.38 \\
\hline 6 month - $99 \%$ & 0.69 & 0.87 & 0.85 & 0.81 & 0.75 & 0.68 & 0.59 & 0.50 & 0.44 \\
\hline 12 month - 99\% & 0.71 & 0.87 & 0.85 & 0.82 & 0.76 & 0.71 & 0.62 & 0.56 & 0.50 \\
\hline Observations & 15872 & 1984 & 1984 & 1984 & 1984 & 1984 & 1984 & 1984 & 1984 \\
\hline
\end{tabular}

Table A.4: Antibody Test Willingness to Pay, by Length and Strength of Immunity

\begin{tabular}{lcccc}
\hline \hline & $(1)$ & $(2)$ & $(3)$ & $(4)$ \\
& $50 \%$ immunity & $70 \%$ immunity & $90 \%$ immunity & $99 \%$ immunity \\
& mean & mean & mean & mean \\
\hline 3-month immunity & 14.39 & 17.14 & 18.62 & 19.61 \\
6-month immunity & 15.82 & 18.41 & 20.03 & 21.24 \\
12-month immunity & 16.32 & 19.53 & 21.50 & 21.94 \\
\hline \hline
\end{tabular}


Non-Hispanic Blacks: COVID-19 Antibody Test Demand, by Strength and Length of Protective Immunity
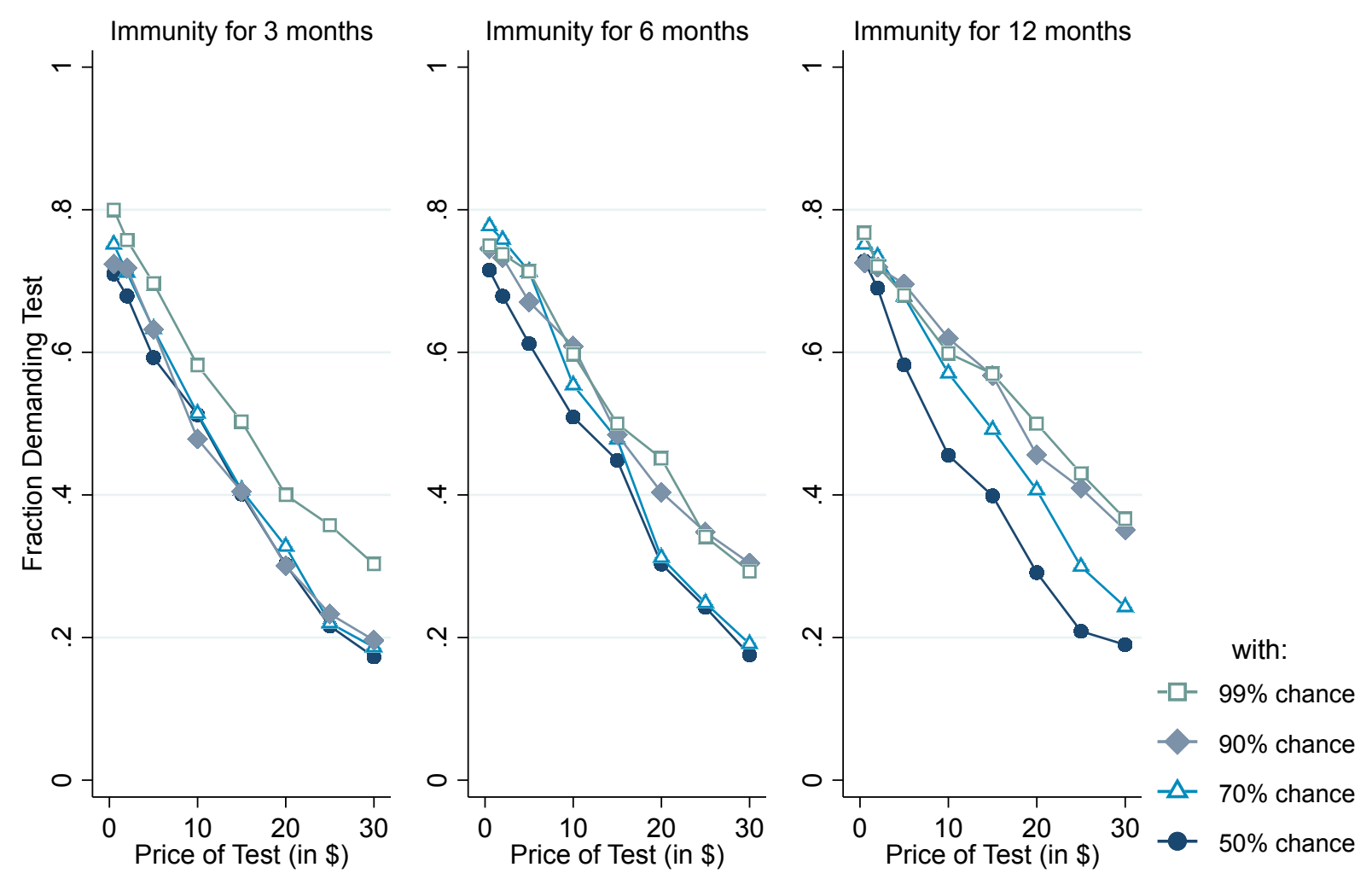

Figure A.1: This figure displays the fraction of non-Hispanic blacks choosing the COVID-19 antibody tests, for each price. Demand is shown for the cases in which protective immunity lasts 3 months (left), 6 months (center), and 12 months (right). In each case, the strength of protective immunity varies between a $99 \%, 90 \%, 70 \%$ or $50 \%$ chance that antibodies offer protection against COVID-19. 
Willingness to Pay for Antibody Tests

By Chance and Length of Protective Immunity
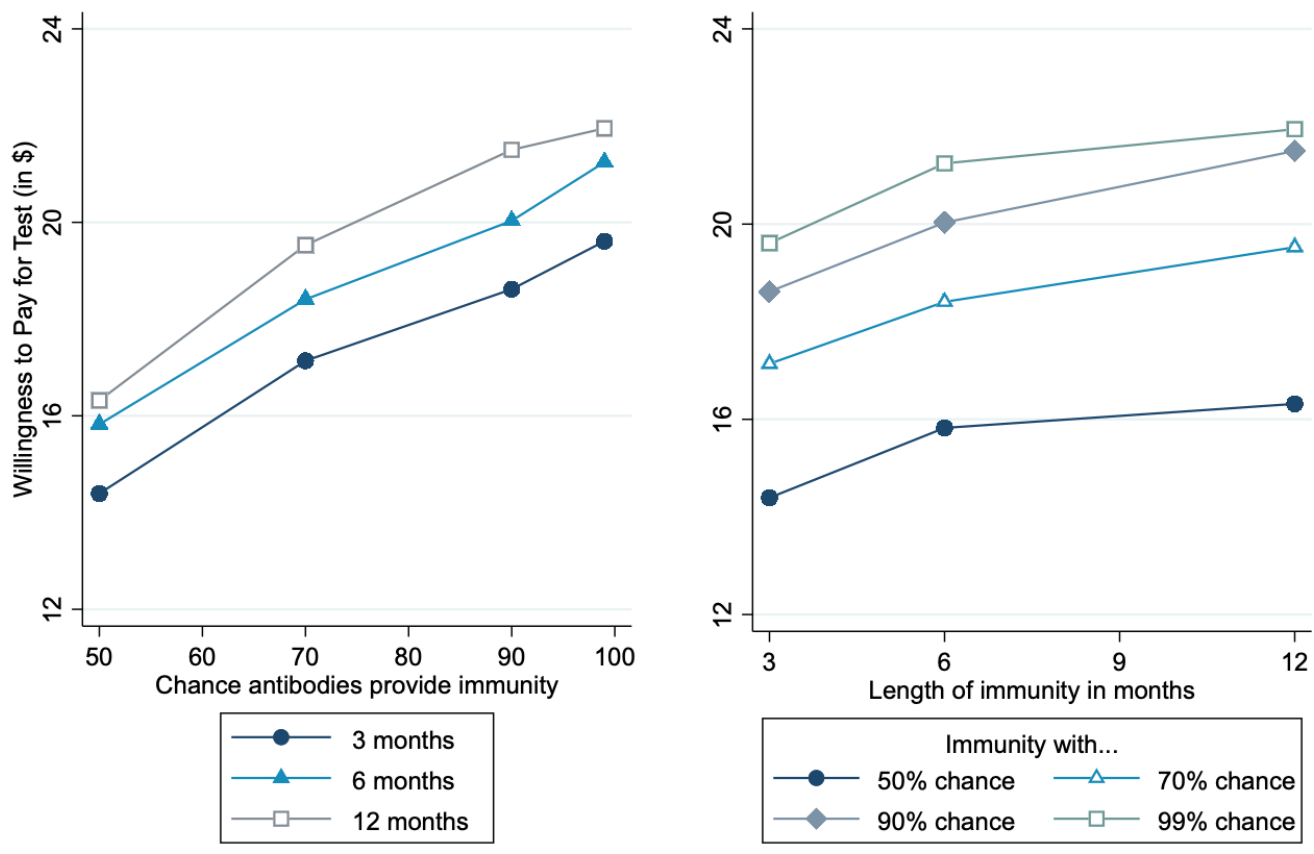

Figure A.2: This figure displays the average willingness to pay for antibody tests, by chance of immunity (left panel) and length of immunity (right panel). 


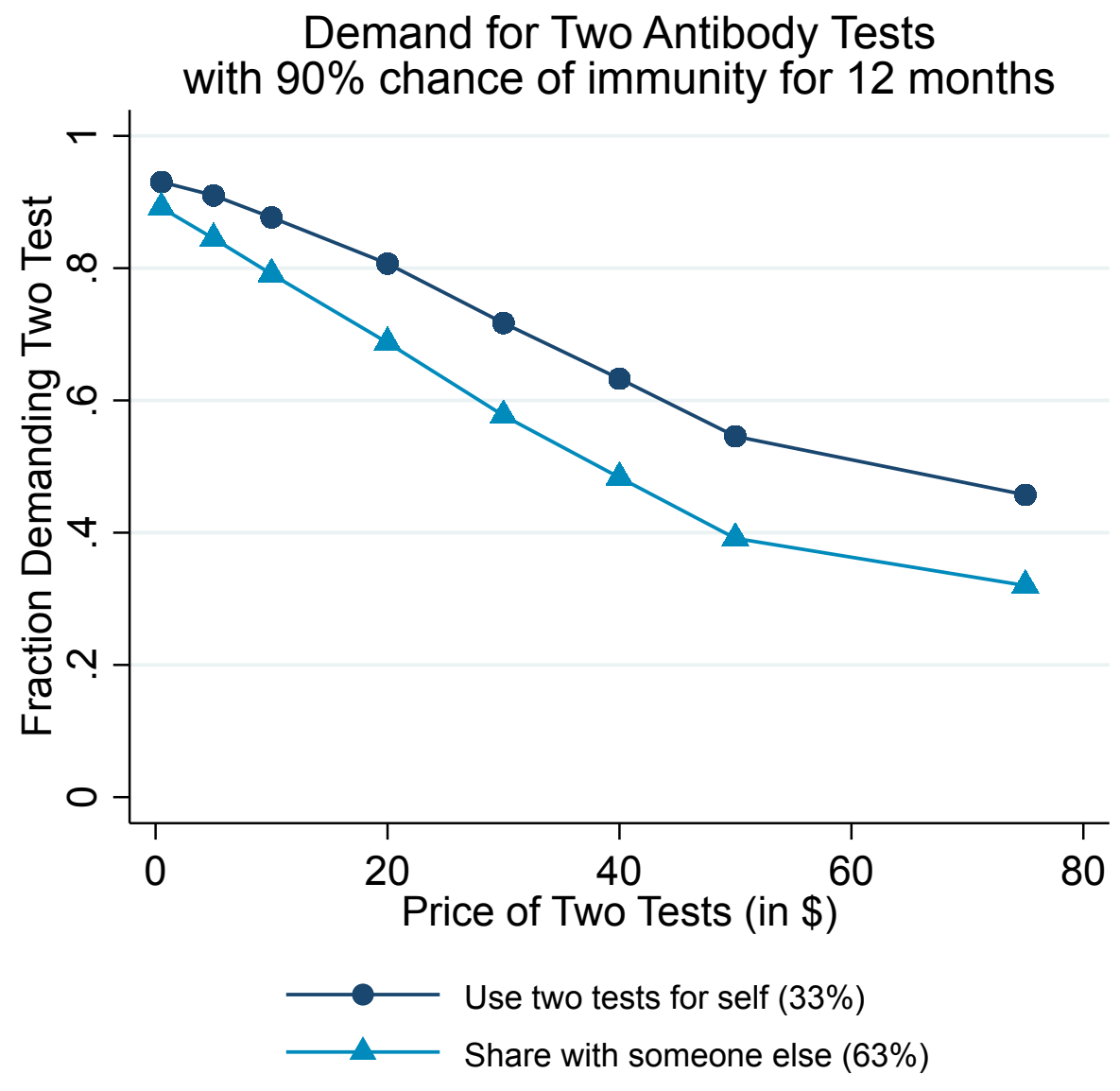

Figure A.3: This figure displays the fraction of subjects who demand the 2 antibody tests, over each available monetary payment, separated by those who indicated they would share the 2 tests with someone else or use them for themselves. 
A.3 Willingness to Pay by State and CDC Statistics 
Table A.5: Willingness to Pay and Beliefs by US State

\begin{tabular}{|c|c|c|c|c|c|c|}
\hline & \multicolumn{3}{|c|}{ CDC Data (May 12, 2020) } & \multicolumn{3}{|c|}{ Study Data } \\
\hline & $\begin{array}{l}\text { Total } \\
\text { Cases }\end{array}$ & $\begin{array}{l}\text { Total } \\
\text { Death }\end{array}$ & $\begin{array}{l}\text { Percent } \\
\text { Category }\end{array}$ & $\begin{array}{c}\text { Belief I } \\
\text { had COVID19 }\end{array}$ & $\begin{array}{l}\text { Willingness } \\
\text { to pay (in \$) }\end{array}$ & $\mathrm{N}$ \\
\hline Alabama & 10413 & 424 & 2 & 20.65 & 18.31 & 26 \\
\hline Alaska & 381 & 10 & 1 & 52.50 & 25.94 & 2 \\
\hline Arizona & 11380 & 542 & 2 & 23.24 & 21.28 & 54 \\
\hline Arkansas & 4043 & 94 & 5 & 26.08 & 17.93 & 13 \\
\hline California & 67939 & 2770 & 5 & 24.93 & 17.92 & 245 \\
\hline Colorado & 19735 & 986 & 2 & 37.77 & 19.19 & 43 \\
\hline Connecticut & 33765 & 3008 & 3 & 34.17 & 22.96 & 18 \\
\hline Delaware & 6741 & 237 & 3 & 25.17 & 21.08 & 6 \\
\hline District of Columbia & 6389 & 328 & 3 & 17.33 & 22.78 & 3 \\
\hline Florida & 40982 & 1735 & 5 & 21.06 & 18.53 & 177 \\
\hline Georgia & 33995 & 1442 & 2 & 23.79 & 15.84 & 77 \\
\hline Hawaii & 582 & 17 & 1 & 20.33 & 11.17 & 3 \\
\hline Idaho & 2260 & 70 & 1 & 28.25 & 10.97 & 4 \\
\hline Illinois & 79007 & 3459 & 3 & 30.80 & 18.53 & 96 \\
\hline Indiana & 24627 & 1540 & 3 & 24.62 & 21.81 & 24 \\
\hline lowa & 12373 & 271 & 3 & 30.10 & 18.12 & 10 \\
\hline Kansas & 7116 & 158 & 2 & 31.75 & 19.60 & 12 \\
\hline Kentucky & 6677 & 311 & 5 & 18.52 & 15.37 & 21 \\
\hline Louisiana & 31881 & 2308 & 2 & 23.44 & 18.33 & 25 \\
\hline Maine & 1462 & 65 & $\overline{5}$ & 14.62 & 18.11 & 8 \\
\hline Maryland & 34061 & 1756 & 3 & 22.38 & 21.29 & 37 \\
\hline Massachusetts & 78462 & 5108 & 2 & 24.00 & 19.51 & 39 \\
\hline Michigan & 47552 & 4584 & 2 & 26.33 & 18.09 & 45 \\
\hline Minnesota & 11799 & 591 & 5 & 26.09 & 19.36 & 32 \\
\hline Mississippi & 9908 & 457 & 5 & 16.70 & 14.08 & 10 \\
\hline Missouri & 9918 & 488 & 5 & 23.32 & 17.40 & 37 \\
\hline Montana & 459 & 16 & 1 & 50.00 & 7.50 & 1 \\
\hline Nebraska & 8572 & 100 & 3 & 22.50 & 16.87 & 14 \\
\hline Nevada & 6163 & 317 & 2 & 27.62 & 22.16 & 26 \\
\hline New Hampshire & 3160 & 133 & 5 & 20.80 & 21.14 & 10 \\
\hline New Jersey & 139945 & 9310 & 4 & 22.14 & 20.99 & 65 \\
\hline New Mexico & 5069 & 208 & 5 & 22.75 & 20.67 & 16 \\
\hline New York & 336017 & 27184 & 3 & 31.60 & 19.33 & 157 \\
\hline North Carolina & 15045 & 550 & 2 & 24.59 & 15.48 & 71 \\
\hline North Dakota & 1518 & 36 & 1 & 33.00 & 20.00 & 1 \\
\hline Ohio & 24777 & 1357 & 5 & 27.33 & 19.08 & 72 \\
\hline Oklahoma & 4439 & 269 & 1 & 29.73 & 14.28 & 22 \\
\hline Oregon & 3286 & 130 & 1 & 28.61 & 20.44 & 18 \\
\hline Pennsylvania & 57154 & 3731 & 2 & 26.16 & 19.83 & 99 \\
\hline Rhode Island & 11450 & 430 & 2 & 25.17 & 15.88 & 6 \\
\hline South Carolina & 7792 & 346 & 2 & 33.62 & 15.75 & 21 \\
\hline South Dakota & 3614 & 34 & 2 & 15.00 & 25.62 & 3 \\
\hline Tennessee & 15622 & 251 & 5 & 22.30 & 19.20 & 33 \\
\hline Texas & 39869 & 1100 & 5 & 21.41 & 18.41 & 149 \\
\hline Utah & 6395 & 72 & 1 & 29.67 & 15.33 & 12 \\
\hline Vermont & 926 & 53 & 1 & 16.00 & 13.33 & 3 \\
\hline Virginia & 25800 & 891 & 2 & 23.20 & 21.04 & 45 \\
\hline Washington & 17122 & 945 & $\overline{5}$ & 28.10 & 19.26 & 31 \\
\hline West Virginia & 1369 & 57 & 1 & 15.00 & 25.21 & 6 \\
\hline Wisconsin & 10418 & 409 & 5 & 24.20 & 19.01 & 35 \\
\hline Wyoming & 669 & 7 & 1 & 66.67 & 11.19 & 3 \\
\hline
\end{tabular}

Notes: Percent category is the percent range of positive cases provided by the CDC under https://www.cdc.gov/covid-data-tracker/index.html. The value of 1 is $0-5 \%, 2$ is $11-20 \%, 3$ is $21-30 \%, 4$ is $31-40 \%$ and 5 is $6-10 \%$ of the population in the state is estimated to have COVID19. 


\section{A.4 Self-reported Planned Behavior after Testing}

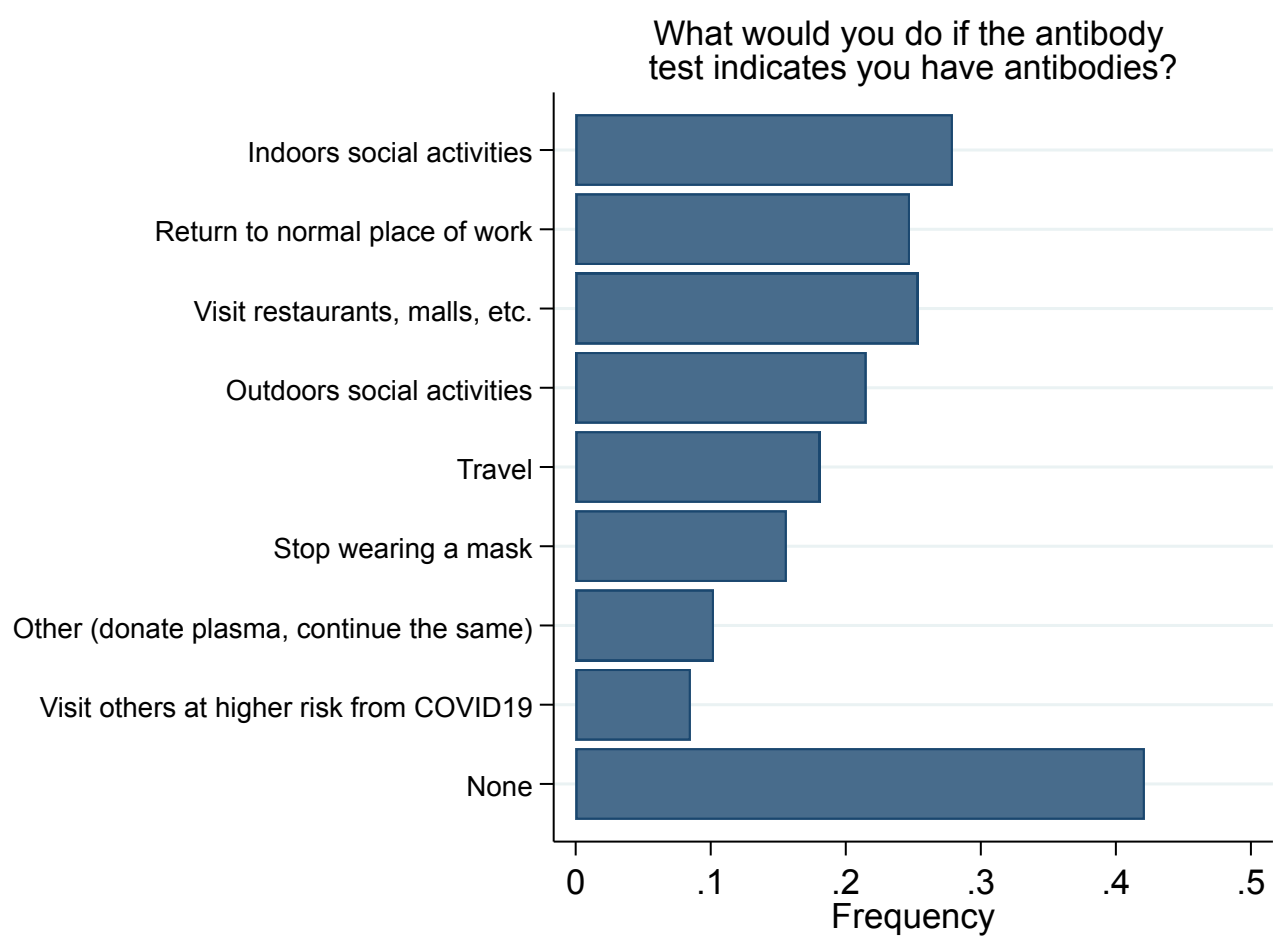

Figure A.4: This figure displays the frequency with which each option was chosen when subjects were asked "Suppose you took a Coronavirus antibody test, and the result came back positive, indicating antibodies. Which of the following behaviors do you think you would engage in immediately after?" They were asked to "assume all these options are possible and legal, but restrictions imposed have not been fully lifted yet." 


\section{Working Paper Series in Economics}

recent issues

No. 140 Marta Serra Garcia and Nora Szech: Understanding demand for COVID-19 antibody Testing, May 2020

No. 139 Fabian Krüger and Lora Pavlova: Quantifying subjective uncertainty in survey expectations, March 2020

No. 138 Michael Müller and Clemens Puppe: Strategy-proofness and responsiveness imply minimal participation, January 2020

No. 137 Andranik S. Tangian: Tackling the Bundestag growth by introducing fraction-valued votes, October 2019

No. 136 Susanne Fuchs-Seliger: Structures of rational behavior in economics, September 2019

No. 135 Cornelia Gremm, David Bälz, Chris Corbo and Kay Mitusch: Intermodal competition between intercity buses and trains - A theoretical model, September 2019

No. 134 Marta Serra-Garcia and Nora Szech: The (in)elasticity of moral ignorance, August 2019

No. 133 Andranik S. Tangian: Composite indicators for computer-aided collective bargaining, July 2019

No. 132 Andranik S. Tangian: Combining the third vote with traditional elections, May 2019

No. 131 Klaus Nehring and Clemens Puppe: Resource allocation by frugal majority rule, April 2019

No. 130 Benedikt Notheisen and Christof Weinhard: The blockchain, plums, and lemons: Information asymmetries \& transparency in decentralized markets, February 2019 